\title{
Eficiência do tratamento de águas residuárias do processamento de café cereja descascado nas Fazendas Rio Doce, Caratinga, Estado de Minas Gerais, Brasil
}

\section{Ottomar Bamberg de Campos, Kleber Ramon Rodrigues, Roberto Silva Martins*, Leopoldo Concepción Loreto Charmelo, Alessandro Saraiva Loreto, Athos Alves Vieira}

Centro Universitário de Caratinga (UNEC). Av. Moacir de Matos, 49. Centro. Caratinga-MG. Brasil (CEP 35300-047).*E-mail: robertosilvamartins@hotmail.com.

Resumo. Para assegurar a sustentabilidade do sistema via úmido de processamento do Coffea arabica L., é necessário que o resíduo líquido proveniente da lavagem e, principalmente, do descascamento seja tratado corretamente. Assim, o objetivo deste trabalho é avaliar a eficiência do tratamento de águas residuárias do processamento de café cereja descascado, através do método das lagoas anaeróbicas e facultativas, de fácil construção, manejo e eficiência. Foi comprovado que a eficiência da metodologia, considerando que para a produção de uma saca de café de $60 \mathrm{~kg}$, com volume aproximado de $480 \mathrm{~L}$ de fruto, pode consumir no sistema tradicional cerca de $2.400 \mathrm{~L}$ de água, enquanto que pelo sistema de tratamento das águas residuárias este número é reduzido pela metade, podendo chegar a apenas $0,5 \mathrm{~L}$ de água por litro de fruto produzido. Este método fornece ainda melhorias através do controle de demanda bioquímica do oxigênio (DBO), evitando o aparecimento das macrófitas e permitindo o controle e a manutenção de um sistema oligotrófico tanto à montante quanto à jusante das lagoas.

Palavras-chave: Coffee arabica L.; Descascamento; Águas residuárias; Sustentabilidade; DBO.

Abstract. Efficiency of wastewater treatment of peeled cherry coffee processing at Fazenda Rio Doce, Caratinga, Minas Gerais States, Brazil. In order to ensure the sustainability of the washed processing system of Coffea arabica L., it is necessary that the liquid residue from the washing and, mainly, the dehulling be treated correctly. Thus, the objective of this work is to evaluate the efficiency of wastewater treatment of the peeled cherry coffee processing, through the anaerobic and facultative lagoons method, of easy construction, management and efficiency. It was verified that the efficiency of the methodology, considering that for the production of a $60 \mathrm{~kg}$ bag of coffee, with an approximate volume of $480 \mathrm{~L}$ of fruit, can consume in the traditional system about 2,400 L of water, whereas by the treatment system this number is reduced by half and can reach only $0.5 \mathrm{~L}$ of water per liter of fruit produced. This method provides further improvements through biochemical oxygen demand (BOD) control, avoiding the emergence of macrophytes and allowing the
Recebido:

$01 / 08 / 2017$

Aceito:

28/12/2017

Publicado:

31/12/2017

Acesso aberto Artigo completo

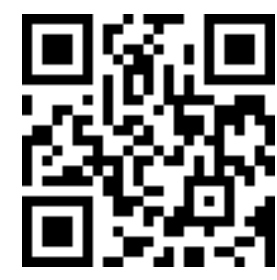

ORCID

(1) 0000-0002-3938-7770 Ottomar Bamberg de Campos

(D) $0000-0002-9122-8419$

Kleber Ramon

Rodrigues

(1) 0000-0002-5907-9716 Roberto Silva Martins

(D) 0000-0003-1120-5979

Leopoldo Concepción

Loreto Charmelo

(D) 0000-0003-4757-6683

Alessandro Saraiva

Loreto

(D) 0000-0002-1214-4410

Athos Alves Vieira 
control and maintenance of an oligotrophic system both upstream and downstream of the lagoons.

Keywords: Coffea arabica L; Peeling; Wastewaters; Sustaintability; BOD.

\section{Introdução}

O café Coffee arabica L. foi cultivado pela primeira vez no continente americano em 1718, no Suriname (região nordeste da América do Sul), quando foi trazido pelos holandeses. Na época, era um importante centro produtor. Em 1727, as primeiras sementes de café chegaram em terras brasileiras, trazidas do Suriname por Francisco Palheta. Começou a ser cultivado no Pará, se expandindo posteriormente para os Estados do Maranhão, Ceará, Pernambuco e Bahia. Em 1774, o café veio do Maranhão para o Rio de Janeiro. Daí expandiuse para as encostas da Serra do Mar, atingindo, em 1825, o Vale do Paraíba, alcançando os Estados de São Paulo e Minas Gerais. Em 1815, chegou ao Espírito Santo e em 1910 ao Paraná (Neves, 1974).

Ainda segundo Neves (1974), a cultura do café foi introduzida na Zona da Mata, em Minas, em meados do século XIX e, historicamente, sempre se produziu café de qualidade inferior, do tipo Rio e Rio Zona. O processo desuniforme de maturação dos grãos, comum nesta região, é atribuído, consequentemente, às diversas floradas naturais do cafeeiro, o que provoca colheita não seletiva. Outro aspecto importante diz respeito às características microclimáticas da região, cuja configuração topográfica favorece a formação de neblina e orvalho na ocasião da colheita e, consequentemente, com o aumento da umidade ambiente, dá-se uma maior atividade microbiana, intensificando o processo fermentativo da mucilagem do café. Consequentemente, florada desigual, maturação desuniforme, colheita não seletiva, ambiente úmido nos frutos, formam um cardápio favorável para a queda da qualidade do café (Pascoal, 2006).

Minas Gerais lidera a produção de café no Brasil respondendo por mais de $55 \%$ da produção nacional. A produção do grão dá-se em praticamente todas as partes do estado, embora existam quatro regiões mais definidas, Sul de Minas, Cerrado Mineiro, Matas de Minas (Zona da Mata e Leste) e a Chapada de Minas (Vales do Jequitinhonha e Mucuri). A produção mineira de 2016 ficou em 30 milhões de sacas (CONAB, 2016).

A adoção da prática de descascamento e/ou despolpamento do café cereja e a consequente separação dos frutos verdes e dos que já passaram do ponto de maturação (secos), constitui a forma ideal para que se possa operacionalizar adequadamente a secagem e obter um produto uniforme, de melhor qualidade e maior cotação no mercado (Sousa e Silva et al., 2013).

A adequação do modelo de tratamento de águas residuárias no processamento do café cereja descascado (CD), visa a devolver este importante insumo (água) ao meio ambiente, de maneira que os corpos hídricos não sejam afetados por carga poluente que possa intervir na vida e na qualidade de suas águas. Assim sendo, fica garantida a sustentabilidade da cafeicultura.

O objetivo do trabalho é avaliar o modelo de tratamento de águas residuárias resultante do descascamento do $\mathrm{CD}$, no sistema "australiano", que consiste em um sistema de lagoas anaeróbias seguidas por lagoa facultativa, onde não há instalação de nenhum equipamento especial, há economia de área e é de fácil construção e manejo, além de ser uma metodologia adequada para os cafeicultores. Também permite diminuir a carga de poluentes da matéria orgânica dissolvida no afluente originário do descascamento do $\mathrm{CD}$, para níveis que não cause poluição no corpo.

\section{Revisão de literatura}

Os efluentes líquidos gerados no sistema de processamento do café CD apresentam Demanda Bioquímica de Oxigênio (DBO) em torno de 12.500 mg/L 
(Souza, 2005), conforme Certificado de Análise $\mathrm{n}^{\circ} \mathrm{Al}$ 21912, do Laboratório de Águas e Resíduos, da Universidade Federal de Viçosa-MG. Este valor é muito acima do permitido pela legislação ambiental para lançamento de efluentes em corpos hídricos. A Deliberação Normativa COPAM nº 10/1986 (Minas Gerais. 1986), orienta que, para lançamento de águas residuárias em corpos hídricos, a DBO seja de $60 \mathrm{mg} / \mathrm{L}$ e que a eficiência do sistema utilizado no processo, para diminuição da carga de DBO, seja superior a 85\% (Souza, 2005). Em outro experimento, Fia et al. (2010) encontrou valores de DBO que variam de $7.836 \mathrm{mg} / \mathrm{L}$ a $12.536 \mathrm{mg} / \mathrm{L}$ em trabalho de avaliação de forrageiras tratadas com águas residuárias do processamento de frutos de café CD.

As lagoas anaeróbias são aquelas em que o processo biológico de oxidação da matéria orgânica é predominantemente anaeróbico, porque não existe oxigênio livre na massa líquida. Os organismos existentes têm que remover o oxigênio dos compostos do afluente residuário, a fim de retirar a energia para sobreviverem (Sperling, 2002).

Segundo Loehr (1974), as lagoas anaeróbias requerem menor área superficial e profundidade adequada para promover condição de anaerobiose, não sendo necessário longo tempo de detenção hidráulica. A remoção do DBO em uma lagoa anaeróbia proporciona substancial economia de área.

Na lagoa facultativa, uma série de mecanismos contribuem para a continuação da purificação da água residuária. Estes mecanismos ocorrem em três camadas da lagoa: no fundo (zona anaeróbia), onde ainda há esse tipo de oxidação; no meio uma zona facultativa; e a camada superficial onde ocorre fotossíntese, pelas algas (zona aeróbia). Nesta camada a matéria orgânica é oxidada por meio de oxidação aeróbia. Há um perfeito equilíbrio entre o consumo e a produção de oxigênio e gás carbônico. $\mathrm{Na}$ respiração pelas bactérias, há consumo de oxigênio e produção de gás carbônico. Na fotossíntese pelas algas, há produção de oxigênio e consumo de gás carbônico (Sperling, 2002).
A zona intermediária, entre a mais profunda e a superficial, é a chamada zona facultativa, onde pode ocorrer maior ou menor concentração de oxigênio. $\mathrm{Na}$ medida em que se aprofunda na lagoa, a penetração de luz é menor e, consequentemente, o consumo de oxigênio é maior (respiração) que a produção (fotossíntese). Além disso, a fotossíntese só ocorre durante o dia, fazendo com que à noite possa prevalecer a ausência de oxigênio. É justamente em virtude dessa condição que se chama de facultativa este tipo de lagoa.

\section{Materiais e métodos}

Para atender as normas ambientais, no sistema em estudo, houve necessidade de três lagoas anaeróbias, uma lagoa facultativa e uma escada de aeração, além de um tratamento preliminar onde é removida a parte sólida, por centrifugação. Isto permite a reciclagem da água por mais tempo, diminuindo seu consumo (Sousa e Silva et al., 2013).

\section{Localização das áreas de estudo \\ O estudo foi realizada nas Fazendas}

Rio Doce, localizadas no Córrego do Rio Preto, Distrito de Santa Luzia, Município de Caratinga, na região leste do Estado de Minas Gerais. Estão inseridas na Região das Matas de Minas, conforme zoneamento das distintas áreas de cafeicultura do estado (Figuras 1 e 2).

O ponto de captação de água para abastecer o sistema é no Córrego dos Paulos, há certificado de outorga para esta captação, que atende plenamente à legislação vigente para a sua vazão (Portaria IGAM $\mathrm{n}^{\circ}$ 010/1998) (Minas Gerais, 1998).

\section{Descrição do processo}

$\mathrm{O}$ equipamento utilizado na propriedade, para lavar e descascar o café apresenta um consumo de água de $2,7 \mathrm{~L}$ para cada litro de café processado. O tempo de trabalho deste processamento é de 6 horas/dia, com a geração de $10.800 \mathrm{~L} / \mathrm{h}$, totalizando cerca de $64.800 \mathrm{~L}$ de afluente líquido a ser tratado diariamente. 


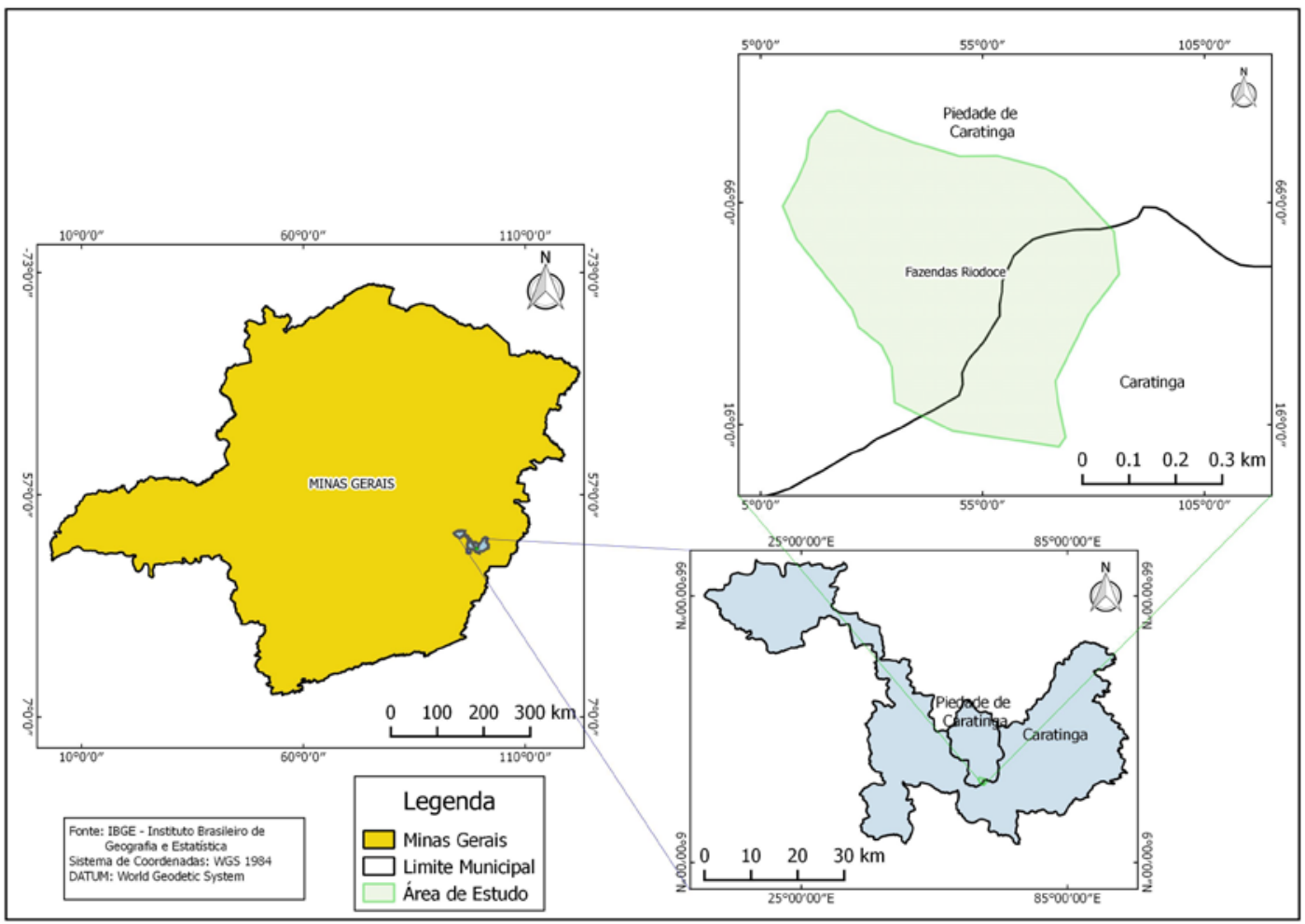

Figura 1. Localização e características gerais da área objeto de estudo.



Figura 2. Localização dos equipamentos. 
Antes de passar para o sistema de tratamento, o efluente passa por um aparelho chamado de eco filtro (tratamento preliminar) onde são separados os resíduos sólidos (munha da casca de café) do líquido. Esta separação se dá por centrifugação. O resíduo sólido é direcionado para o depósito de casca melosa, onde, posteriormente, é utilizado como adubação orgânica e/ou cobertura morta nos talhões mais debilitados da lavoura de café. Apresenta teores médios de $3,0 \%$ de $\mathrm{N}$, $0,15 \%$ de $\mathrm{P}_{2} \mathrm{O}_{5}$ e $3,9 \%$ de $\mathrm{K}_{2} \mathrm{O}$ (Fundação Procafé, 2015).

O resíduo líquido ainda passa por uma caixa de armazenamento de $10.000 \mathrm{~L}$, onde é reciclado para o sistema, a fim de se economizar água. Somente após apresentarse mais denso, é que é bombeado para o sistema de tratamento.

Este afluente gerado $(64.800 \mathrm{~L})$, é proveniente de um processamento de aproximadamente $45 \%$ da produção de café desta propriedade. Historicamente, a produção de CD é de 3.600 sacas de $60 \mathrm{~kg}$ por ano, o equivalente a $1.800 \mathrm{~m}^{3}$ de café que sai das lavouras e que são processados, considerando que se gasta aproximadamente $500 \mathrm{~L}$ de cerejas para se fazer uma saca de café beneficiado.

Para o dimensionamento das lagoas anaeróbias e da facultativa, além dos fatores acima de produção de café, produtividade e equipamentos, foram levados em consideração as seguintes variáveis:

- Taxa de aplicação volumétrica.

- Tempo de detenção.

- Profundidade.

- Geometria.

\section{Taxa de aplicação volumétrica}

(Lv)

É o principal item para a construção do sistema de lagoas anaeróbias sendo estabelecido em função da necessidade de um determinado volume de lagoa para conversão da carga de DBO aplicada. Depende da temperatura média do ar no mês mais frio do ano, critério adotado por Mara (1997) e Sperling (2002). Serve para definir o volume das lagoas requeridas $\left(\mathrm{m}^{3}\right)$, para o sistema. Varia de 0,1 a $0,35 \mathrm{~kg}$ de $\mathrm{DBO} / \mathrm{m}^{3} / \mathrm{d}$, e é obtido pela equação:

$$
\mathrm{V}=\mathrm{L} / \mathrm{LV}
$$

Onde:

$\left(m^{3}\right)$.

$\mathrm{V}=$ volume requerido pelas lagoas

$\mathrm{L}=$ carga de DBO total do afluente.

Lv = taxa de aplicação volumétrica

( $\left.\mathrm{kg} \mathrm{DBO} / \mathrm{m}^{3} / \mathrm{d}\right)$.

A temperatura média do mês mais frio é de $18^{\circ} \mathrm{C}$ (medição próxima ao local do sistema). Consequentemente, pelo critério do autor acima, chega-se ao valor de $\mathrm{Lv}=0,22 \mathrm{~kg} \mathrm{DBO} / \mathrm{m}^{3}$.d.

Vazão diária $=64,8 \mathrm{~m}^{3} /$ dia

DBO do afluente $=12.500 \mathrm{mg} / \mathrm{L}$

Valor $\mathrm{L}=64,8 \mathrm{~m}^{3} / \mathrm{dia} \times 12.500$

$\mathrm{mg} / \mathrm{L}$

$\mathrm{L}=810 \mathrm{~kg}$ de $\mathrm{DBO} / \mathrm{dia}$

Volume requerido (V) das lagoas:

$\mathrm{V}=\mathrm{L} / \mathrm{Lv}=810 \mathrm{~kg} \mathrm{de}$

DBO/dia/0,22 kg de DBO $/ \mathrm{m}^{3} / \mathrm{d}$

$\mathrm{V}=3.680 \mathrm{~m}^{3}$

\section{Tempo de detenção (t)}

Está associado ao volume requerido e à vazão do afluente originário do processamento do café CD.

$$
\begin{aligned}
& \mathrm{t}=\mathrm{V} / \mathrm{Q} \\
& \mathrm{V}=\text { volume da lagoa }\left(\mathrm{m}^{3}\right)=3680 \\
& \mathrm{Q}=\text { vazão do afluente }\left(\mathrm{m}^{3} / \mathrm{d}\right)=64,8
\end{aligned}
$$

$\mathrm{m}^{3} / \mathrm{dia}$

Serve para se determinar a quantidade de dias que o efluente necessita ficar em uma lagoa para que a depuração aeróbia se concretize satisfatoriamente.

57 dias

$$
\mathrm{t}=\mathrm{V} / \mathrm{Q}=3.680 \mathrm{~m}^{3} / 64,8 \mathrm{~m}^{3} / \mathrm{dia}=
$$

\section{Profundidade (H)}

$$
\mathrm{H}=3,5 \mathrm{~m} \text { (adotado) }
$$


Foi adotado este valor a fim de proporcionar as condições anaeróbias do ambiente e um custo acessível de construção. Uma profundidade maior é desejável porque evita que a lagoa anaeróbia trabalhe como facultativa. Escavações profundas tendem a ser mais caras. Os valores mais usados estão na faixa de 3,5 a 5,0 m.

\section{Geometria}

As lagoas anaeróbias podem ser quadradas ou retangulares, com relação ao comprimento/largura, variando de 1 a 5 . As dimensões estão apresentadas no Tabela 2 e são em função do dimensionamento do sistema (volume de água e aporte do efluente e período de detenção), e da topografia do terreno. Também se levou em consideração a proximidade da usina de processamento de café, a direção dos ventos, nível de lençol freático, características do solo e ausência de residência no entorno, pois há possibilidade de maus odores.

Adotou-se três lagoas anaeróbias, cujas medidas atendem ao volume gerado de água residuária do processamento de café da Fazenda, os seus respectivos períodos de detenção e a eficiência de cada uma em reduzir a carga de poluição.

A capacidade das mesmas é ligeiramente maior que o necessário, para eventual aumento de produção de $\mathrm{CD}$, mas dentro dos limites de um custo de construção e manutenção adequados.

Tabela 1. Dimensionamento das lagoas anaeróbias.

\begin{tabular}{|l|c|c|c|c|}
\hline & $\begin{array}{c}\text { Volume diário de aporte } \\
\text { de efluente } \mathbf{( m}^{\mathbf{3}} \mathbf{)}\end{array}$ & $\begin{array}{c}\text { Período de } \\
\text { detenção (dias) }\end{array}$ & $\begin{array}{c}\text { Volume da lagoa } \\
\left(\mathbf{m}^{\mathbf{3}} \mathbf{)}\right.\end{array}$ & Área $\mathbf{( m}^{\mathbf{2}} \mathbf{)}$ \\
\hline Lagoa 1 & 64,8 & 24 & 1.570 & 450 \\
\hline Lagoa 2 & 64,8 & 12 & 755 & 220 \\
\hline Lagoa 3 & 64,8 & 6 & 420 & 120 \\
\hline
\end{tabular}

Tabela 2. Dimensões das lagoas na Fazenda Rio Doce.

\begin{tabular}{|l|c|c|c|}
\hline & Comprimento (m) & Largura (m) & Profundidade (m) \\
\hline Lagoa 1 & 50 & 9 & 3,5 \\
\hline Lagoa 2 & 24 & 9 & 3,5 \\
\hline Lagoa 3 & 15 & 8 & 3,5 \\
\hline
\end{tabular}

\section{Dimensionamento da lagoa facultativa}

A profundidade foi estimada em $2 \mathrm{~m}$ para que possa acontecer penetração de raios solares em toda sua extensão, a fim de favorecer a fotossíntese na camada superior. Para as outras medidas da geometria, houve uma maior flexibilidade, pois foi adotada lagoa mais alongada, porque não há sobrecarga de poluente no trecho inicial da mesma. Houve uma acentuada remoção da carga de DBO nas lagoas anaeróbias.

Em função da topografia do terreno, do tempo de retenção (15 dias) e do aporte diário de efluente originário das lagoas anaeróbias $\left(64,8 \mathrm{~m}^{3}\right)$, adotou-se um comprimento de $50 \mathrm{~m}$. As medidas completas estão no Tabela 3. 


\section{Escada de aeração}

Na parte final do sistema, há uma escada de aeração. A escada de aeração não tem o objetivo de redução de DBO e sim aumentar a taxa de oxigênio dissolvido no efluente tratado. Admite-se que cada degrau de $0,25 \mathrm{~m}$ de queda livre de líquido apresenta uma capacidade de absorção de oxigênio de 1,72 mg/L (Souza, 2005). Por questões ambientais a quantidade mínima de oxigênio dissolvido no efluente deve ser de 4,0 $\mathrm{mg} / \mathrm{L}$, e, considerando que este efluente saia com $0 \mathrm{mg} / \mathrm{L}$ de oxigênio dissolvido, pode-se calcular a quantidade de degraus que são necessários para atender a demanda: degraus

$4 \mathrm{mg} / \mathrm{L}=1,72 \mathrm{mg} / \mathrm{L} \times \mathrm{n}^{\circ}$ de $\mathrm{N}^{\circ}$ de degraus $=2,32$ degraus $=$ 3 degraus

Tabela 3. Dimensionamento da lagoa facultativa.

\begin{tabular}{|c|c|c|c|}
\hline $\begin{array}{l}\text { Volume diário de aporte } \\
\text { de afluentes }\left(\mathrm{m}^{3}\right)\end{array}$ & $\begin{array}{c}\text { Período de detenção } \\
\text { (dias) }\end{array}$ & Volume $\left(\mathrm{m}^{3}\right)$ & Área $\left(\mathrm{m}^{2}\right)$ \\
\hline 64,8 & 15 & 1000 & 500 \\
\hline Comprimento (m) & \multicolumn{3}{|c|}{ Profundidade (m) } \\
\hline 50 & 10 & & 2 \\
\hline
\end{tabular}

A carga afluente que se direciona à lagoa facultativa é a mesma que entrou na lagoa anaeróbia.

Como há uma diferença de nível considerável entre a área do sistema e o corpo receptor, foi construído um número maior de degraus (23), pois haverá benefícios adicionais. Além disso, a escada maior impede erosão e desbarrancamento.

Após a escada de aeração, o efluente já apresenta condições de ser lançado no curso d'água receptor (Córrego dos Paulos). As análises das águas do Córrego dos Paulos são feitas anualmente. Os resultados da análise de pontos a montante e a jusante do ponto de captação são realizados no Laboratório Água Limpa, de Manhuaçu-MG.

\section{Resultados e discussões}

A análise das águas realizadas em Laboratório confirma a citação de Sperling (2002) e atende totalmente as normas dos órgãos públicos Estadual (COPAM) e
Nacional (CONAMA). Há redução da carga de DBO, conforme a revisão de literatura, embora no ano de 2015 houve significativo aumento da carga de DBO, considerando os resultados das análises de amostras de águas à montante e à jusante em relação ao ponto de captação. Mesmo assim, dentro dos padrões permitidos pela legislação. O tratamento da água residuária do café apresentado neste trabalho, demonstra claramente a eficiência do processo.

Em 2011, o aumento foi menor (19,5\%) possivelmente porque foi ano de baixa produção (bienalidade) e volume pequeno vazou pela escada de aeração. Outrossim, a remoção dos resíduos sólidos contidos na água residuária possibilita que ela seja reutilizada durante mais tempo no processamento, diminuindo o seu consumo (Sousa e Silva et al., 2013) A tal ponto que nos anos de safra baixa pode não vazar água na escada de aeração. 
Tabela 4. Comparativo de safra do café com produtividade bienal.

\begin{tabular}{|l|c|c|c|c|}
\hline Ano & Bienalidade & $\begin{array}{c}\text { Coleta à } \\
\text { montante (mg/L) }\end{array}$ & $\begin{array}{c}\text { Coleta à jusante } \\
(\mathbf{m g} / \mathbf{L})\end{array}$ & $\mathbf{\%}$ \\
\hline 2015 & Safra alta & 1,05 & 2,03 & 100 \\
\hline 2011 & Safra baixa & 0,92 & 1,08 & 19,5 \\
\hline
\end{tabular}

\section{Considerações finais}

Com mercados cada vez mais organizados e consumidores cada vez mais conscientizados sobre os alimentos a que se propõem consumir, a produção de cafés descascados, desmucilados ou não, apresenta-se como uma saída viável para os produtores, principalmente os das Matas de Minas onde o clima conspira contra a produção de cafés finos.

Nas provas de classificação e bebida estes cafés apresentam notas acima de 80 pontos, o que os tornam "cafés especiais" com corpo, doçura e acidez acentuada, com bastante equilíbrio, semelhantes aos "finos" da Colômbia e América Central.

Outras vantagens do processamento de CD, são a efetiva diminuição de custo na pós-colheita do café descascado, ocupa menor área de terreiro, necessita de um menor número de secadores mecânicos, na armazenagem ocupa menos espaço e consequentemente estas vantagens proporcionam menor gasto com mão de obra.

Há considerável quantidade de resíduos sólidos (casca melosa e munha obtida do tratamento preliminar) que, ao serem devolvidos para os talhões mais fracos da lavoura, dá-se um revigoramento na área, tanto na parte biológica quanto física e química do solo.

A cafeicultura, sendo a atividade principal desta propriedade, torna-a sustentável naturalmente aos olhos das autoridades ambientais, das certificadoras, do mercado e dos consumidores.

\section{Declaração de conflito de interesses}

Os autores declaram não haver conflito de interesses.

\section{Referências}

Brasil. Resolução CONAMA no 430, de 13 de março de 2011. Disponível em: $<$ http://www.mma.gov.br/port/conama/legiabre. cfm?coddeg=646>. Acesso em: 28 jun. 2017.

CONAB - Companhia Nacional de Abastecimento. Acompanhamento da Safra Brasileira - Café, v. 3, n. 4, p. 1-77, 2016. Disponível em: <http://www.conab.gov.br/ OlalaCMS/uploads/arquivos/16_12_27_16_26_ 51_boletim_cafe_portugues_-_40_lev__dez.pdf $>$. Acesso em: 28 jun. 2017.

Fia, R.; Matos, A. T. ; Fia, F. R. L.; Matos, M. P.; Lambert, T. F.; Nascimento, F. S. Desenvolvimento de forrageiras em sistemas alagados de tratamento de águas residuárias do processamento do café. Revista Brasileira de Engenharia Agrícola e Ambiental, v. 14, n. 8, p. 1323-1329, 2010. https://doi.org/10.1590/ S1415-43662010000800008

Fundação Procafé. Folha Técnica $\mathbf{n}^{0} 179$ - A palha de café deve ser usada na adubação da lavoura. 2015. Disponível em: $<$ http://fundacaoprocafe.com.br/sites/default/file s/publicacoes/pdf/folhas/Folha 179 - A palha de café deve ser usada na adubação da lavoura.pdf>. Acesso em: 15 dez. 2015.

Loehr, R. C. Agricultural waste management: problems, processes and approaches. New York: Academic Press, 1974.

Mara, D. D. Design manual for waste stabilization ponds in India. Leeds: Lagoon Technology International, 1997.

Minas Gerais. Deliberação Normativa $\operatorname{COPAM~n}^{\circ} 10$, de 16 de dezembro de 1986. Disponível em: <http://www.siam.mg.gov.br/ sla/action/Consulta.do>. Acesso em: 28 nov. 2016.

Minas Gerais. Portaria IGAM n ${ }^{0} 10$, de 30 de dezembro de 1998 . Disponível em: $<$ http://www.siam.mg.gov.br/sla/action/Consult a.do>. Acesso em 28 jun. 2017.

Neves, C. A estória do café. Rio de Janeiro: Instituto Brasileiro do Café, 1974. 
Pascoal, L. N. Aroma de café: guia prático para apreciadores de café. 2. ed. Campinas: Fundação Educar DPaschoal, 2006.

Silva, M. D. S. A. Análises físico-químicas para controle de estações de tratamento de esgotos. São Paulo: CETESB, 1977.

Sousa e Silva, J.; Moreli, A. P.; Soares, S. F.; Donzeles, S. M. L.; Vitor, D. G. Produção de café cereja descascado: equipamentos e custos de processamento. Comunicado Técnico, 4, p. 1-16, 2013. Disponível em: <http://www.sapc.embrapa.br/arquivos/consorci o/comunicadotecnico/comunicado_tecnico_04.p df>. Acesso em 28 jun. 2017.

Souza, C. M. Plano de Controle Ambiental: Fazenda Ouro Verde. Caratinga, 2005.

Sperling, M. Lagoas de estabilização. 2. ed. Belo Horizonte: UFMG, 2002.

Informação da Licença: Este é um artigo Open Access distribuído sob os termos da Licença Creative Commons Attribution, que permite uso irrestrito, distribuição e reprodução em qualquer meio, desde que a obra original seja devidamente citada. 